University of Wollongong

Research Online

Faculty of Engineering and Information

Faculty of Engineering and Information

Sciences - Papers: Part A

Sciences

$1-1-2014$

Effects of temperature and strain rate on microstructure and mechanical properties of high chromium cast iron/low carbon steel bimetal prepared by hot diffusion-compression bonding

\author{
Xingjian Gao \\ University of Wollongong, xg306@uowmail.edu.au \\ Zhengyi Jiang \\ University of Wollongong, jiang@uow.edu.au \\ Dongbin Wei \\ University of Technology Sydney, dwei@uow.edu.au \\ Sihai Jiao \\ Baosteel, Baosteel Research Institute \\ Dengfu Chen \\ Chongqing University
}

See next page for additional authors

Follow this and additional works at: https://ro.uow.edu.au/eispapers

Part of the Engineering Commons, and the Science and Technology Studies Commons

Research Online is the open access institutional repository for the University of Wollongong. For further information contact the UOW Library: research-pubs@uow.edu.au 


\title{
Effects of temperature and strain rate on microstructure and mechanical properties of high chromium cast iron/low carbon steel bimetal prepared by hot diffusion-compression bonding
}

\begin{abstract}
The objective of this study is to develop a hot diffusion-compression bonding process for cladding low carbon steel (LCS) to high chromium cast iron ( $\mathrm{HCCl})$ in solid-state. The influence of temperature (950-1150 degrees $C$ ) and strain rate (0.001-1 s (1)) on microstructure, hardness and bond strength of the $\mathrm{HCCl} / \mathrm{LCS}$ bimetal were investigated. The interface microstructure reveals that the unbonded region can only be found for 950 degrees $C$ due to lack of diffusion, while the intergrowth between the constituent metals occurred at and above 1100 degrees $\mathrm{C}$. When bonding temperature increases to 1150 degrees $\mathrm{C}$, a carbide-free zone was observed near the interface on the $\mathrm{HCCl}$ layer, and the thickness of the zone decreases with an increase of bonding strain rate. These evolutions indicate that the bond quality was improved by raising temperature and reducing strain rate due to the increase of element diffusion. The hot compression process of the bonding treatment not only changes the carbide orientation of the $\mathrm{HCCl}$, but also increases the volume fraction of $\mathrm{Cr}$-carbide. Based on the microstructural examinations and mechanical tests, the optimum bonding temperature and bonding strain rate are determined to be 1150 degrees $C$ and $0.001 \mathrm{~s}(1)$, respectively.
\end{abstract}

\section{Keywords}

diffusion, hot, prepared, bimetal, steel, carbon, low, iron, cast, chromium, high, bonding, properties, compression, mechanical, microstructure, rate, strain, temperature, effects

Disciplines

Engineering | Science and Technology Studies

\section{Publication Details}

Gao, X., Jiang, Z., Wei, D., Jiao, S., Chen, D., Xu, J., Zhang, X. \& Gong, D. (2014). Effects of temperature and strain rate on microstructure and mechanical properties of high chromium cast iron/low carbon steel bimetal prepared by hot diffusion-compression bonding. Materials and Design, 63 650-657.

\section{Authors}

Xingjian Gao, Zhengyi Jiang, Dongbin Wei, Sihai Jiao, Dengfu Chen, Jianzhong Xu, Xiaoming Zhang, and Dianyao Gong 


\section{Effects of temperature and strain rate on microstructure and mechanical properties of high chromium cast iron / low carbon steel bimetal prepared by hot diffusion-compression bonding}

Xingjian Gao ${ }^{\mathrm{a}, \mathrm{b}}$, Zhengyi Jiang ${ }^{\mathrm{a}, \mathrm{c},}{ }^{*}$, Dongbin $\mathrm{Wei}^{\mathrm{a}, \mathrm{d}}$, Sihai Jiao ${ }^{\mathrm{e}}$, Dengfu Chen ${ }^{\mathrm{b}}$, Jianzhong $\mathrm{Xu}^{\mathrm{f}}{ }^{*}{ }^{*}$ Xiaoming Zhang ${ }^{\mathrm{f}}$, Dianyao Gong ${ }^{\mathrm{f}}$

a School of Mechanical, Materials and Mechatronic Engineering, University of Wollongong, Wollongong NSW 2522, Australia

${ }^{\mathrm{b}}$ College of Materials Science and Engineering, Chongqing University, Chongqing 400044, China

${ }^{\text {c }}$ School of Materials and Metallurgy, University of Science and Technology Liaoning, Anshan 114051, China

${ }^{\mathrm{d}}$ School of Electrical, Mechanical and Mechatronic Systems, University of Technology, Sydney NSW 2007, Australia

${ }^{\text {e } B a o s t e e l ~ R e s e a r c h ~ I n s t i t u t e, ~ B a o s h a n ~ I r o n ~ \& ~ S t e e l ~ C o ~ L t d ., ~ S h a n g h a i ~ 200941, ~ C h i n a ~}$

${ }^{\mathrm{f}}$ State Key Laboratory of Rolling and Automation, Northeastern Univertity, Shengyang 110004, China ${ }^{*}$ Corresponding authors: Z.Y. Jiang, Tel: 612 4221 4545, Fax: 612 42215474, Email: jiang@uow.edu.au; J. Xu, Tel: 8624 83687220,Fax: 8624 23906472, Email: xujz@ral.neu.edu.cn

\section{Abstract}

The objective of this study is to develop a hot diffusion-compression bonding process for cladding low carbon steel (LCS) to high chromium cast iron (HCCI) in solid-state. The influence of temperature (950-1150 $\left.{ }^{\circ} \mathrm{C}\right)$ and strain rate (0.001-1 s $\left.{ }^{-1}\right)$ on microstructure, hardness and bond strength of the HCCI / LCS bimetal were investigated. The interface microstructure reveals that the unbonded region can only be found for $950{ }^{\circ} \mathrm{C}$ due to lack of diffusion, while the intergrowth between the constituent metals occurred at and above $1100{ }^{\circ} \mathrm{C}$. When bonding temperature increases to $1150{ }^{\circ} \mathrm{C}$, a carbide-free zone was observed near the interface on the HCCI layer, and the thickness of the zone decreases with an increase of bonding strain rate. These evolutions indicate that the bond quality was improved by raising temperature and reducing strain rate due to the increase of element diffusion. The hot compression process of the bonding treatment not only changes the carbide orientation of the HCCI, but also 
increases the volume fraction of Cr-carbide. Based on the microstructural examinations and mechanical tests, the optimum bonding temperature and bonding strain rate are determined to be $1150{ }^{\circ} \mathrm{C}$ and 0.001 $\mathrm{s}^{-1}$, respectively.

Keywords: Bonding temperature; Strain rate; Bimetal; Diffusion; Hot compression; Interface.

\section{Introduction}

High chromium cast irons (HCCIs) with high-volume fraction of hard Cr-carbides and relatively soft ferrous matrix have been widely used in industrial applications, such as mining, mineral processing and cement manufacturing [1-3]. However, inherent embrittlement and poor ductility as well as inferior weld ability are always keeping a lid on their further utilisation [4, 5]. Recently, a novel bimetal consisting of high chromium cast iron (HCCI) and low carbon steel (LCS) or medium carbon steel (MCS) has been developed to overcome those shortcomings by absorbing the advantages (i.e. excellent ductility and superior weld ability) of the latter component, while maintaining excellent wear resistance of the former component [6-16]. According to previous research, the HCCI / LCS bimetal can be fabricated by composite casting [6-12], diffusion bonding [13, 14] and cast cladding with hot rolling [15, 16]. Oh et al. [6] and Kim et al. [7] reported an advanced duocasting method in which the HCCI ( $\sim 27$ wt\% Cr) was cast first, and then inserted into the other mould to cast the LCS. The resulting duocast material is mechanically bonded into an appropriate geometrical shape. By exchanging the sequence of casting, Sallam et al. [8] produced bimetal beams using duocasting method via pouring the molten HCCI (19.2 wt\% Cr) to clad the solid AISI4140 steel. The mechanical joint was achieved, and the flexural strengths of the bimetal beams can reach up to $790 \mathrm{MPa}$. Moreover, Cholewa et al. [9] presented a so-called mould cavity preparation method by casting the molten gray cast iron to bond with the solid high chromium steel (18 wt\% Cr). The bonding interface was defect-free with a good diffusion connection. Xiong et al. [10, 11] compared the liquid-solid casting method with and without electromagnetic induction field by casting the HCCI (14.21 wt\% Cr) into a sand mould with the pre-set MCS. The results showed that there is a critical volume ratio of HCCI to MCS for realising metallurgical bonding, and the electromagnetic induction field is beneficial to improving bond quality by electromagnetic stirring which cleans the interface and profits the element diffusion. Based on lost 
foam casting, Xiao et al. [12] proposed a liquid-liquid composing process by pouring HCCI ( 22 wt\% Cr) and LCS into the same cavity successively to produce bimetallic linear. The combination region between the components was staggered like dog-tooth without mixture of alloys.

On the other hand, a solid-state diffusion bonding process, which joints HCCI (23.8 wt\% Cr) and LCS at the temperature range of $1173-1273 \mathrm{~K}$, was carried out by Sakurai et al. [13] in air. When this bimetal was tested using an impact wear tester, the wear ratio was equal to the raw material and it did not separate in the bonded area. Likewise, Eroglu and Kurt [14] investigated the effects of temperature and holding time on the diffusion bonding of HCCI (21.76 wt\% Cr) to LCS in an argon atmosphere. It was concluded that a high temperature with a long holding time must be used for enhancing bond strength. Unlike bonding processes without plastic deformation as described above, Xie et al. [15, 16] studied the possibilities of implementing hot rolling on HCCI (12.77 wt\% Cr) with LCS cladding which was prepared by composite casting. A perfect metallurgical bonding was revealed by the continuous distributions of elements, and the compatible deformation of HCCI together with LCS cladding was observed.

In the light of previous research, a new idea of joining HCCI (23 wt\% Cr) and LCS by integrating diffusion and hot forging processes was proposed in this study for the sake of simplifying the bonding process with an improvement of bond quality and mechanical properties. The influence of temperature and strain rate on microstructure and mechanical behaviour of the HCCI / LCS bimetal was evaluated via micro examinations and mechanical tests. The optimum bonding conditions were determined based on the significant investigations.

\section{Experimental procedure}

As-cast hypoeutectic HCCI and commercial hot-rolled LCS sheet were selected as the raw materials, which are responsible for excellent wear resistance and superior toughness, respectively. The chemical compositions of the HCCI and the LCS are given in Table 1. In order to simulate hot forging process, a Gleeble 3500 thermomechanical simulator was employed to carry out the bonding experiments by means of hot compression tests. It is recognised that the Gleeble is a fully integrated digital closed loop 
control thermal and mechanical testing system, which can be used to simulate various processes [17] like continuous casting, hot rolling, forging, extrusion and welding, etc. The cylindrical HCCI samples of $10 \mathrm{~mm}$ diameter and $6 \mathrm{~mm}$ thickness were wire cut from the same ingot in the same direction, while the LCS discs were prepared with $10 \mathrm{~mm}$ diameter and $3 \mathrm{~mm}$ thickness. Before joining, all the faying surfaces were polished to $1 \mu \mathrm{m}$ diamond finish and cleaned by ethanol. Afterwards, HCCI sample was cladded by LCS discs on the both sides to form a sandwich structural assembly. The assembly was placed in the testing chamber and fixed between the anvils, and then subjected to hot diffusioncompression bonding in a low vacuum. The test temperature range is $950-1150{ }^{\circ} \mathrm{C}$ with an interval of $50{ }^{\circ} \mathrm{C}$ and the equivalent strain rates are $0.001,0.01,0.1,1 \mathrm{~s}^{-1}$. Fig. 1 shows the schematic diagram of the assembly and the history of hot diffusion-compression bonding process. In each test, $70 \%$ of thickness reduction of the assembly was conducted.

To examine bond quality, all the bimetal specimens were machined across the interface (i.e. X-Y plane as shown in Fig. 1(b)), and then mounted and polished to $1 \mu \mathrm{m}$ diamond finish followed by etching with a solution of $5 \%$ ferric chloride, $25 \%$ hydrochloric and $70 \%$ distilled water. The interfacial microstructure was detected using scanning electron microscope (SEM) equipped with energy dispersive spectroscope (EDS). In addition, the microstructure evolution of the HCCI layer in its transverse section (i.e. Y-Z plane as shown in Fig. 1(b)) was analysed by optical microscope (OM), and images were processed with the help of the software "ImagePro" to measure the volume fraction of Crcarbide. The phase components of the HCCI were determined by X-ray diffractometer (XRD) using

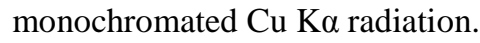

Mechanical properties of the bimetal specimens were surveyed according to hardness and shear strength at room temperature. Microhardness profiles across the interface were obtained by a Vickers hardness tester using $25 \mathrm{~g}$ load for $10 \mathrm{~s}$, and each hardness value is the average of 5 measurements. The shear test sample was machined with dimensions of $3 \mathrm{~mm} \times 3 \mathrm{~mm} \times 1 \mathrm{~mm}$. A tailor-made testing apparatus was designed to conduct the shear tests on the Gleeble thermomechanical simulator at a tensile speed of $0.5 \mathrm{~mm} / \mathrm{min}$. Fig. 2 shows the schematic diagram of the tailor-made apparatus. The bond strength was calculated as Eq. (1), and each strength value is the average of 3 measurements. Moreover, the shear fracture surfaces were examined using SEM. 


$$
\sigma_{\text {bond }}=\frac{F_{\text {ultimate }}}{A_{\text {bond }}}
$$

where $\sigma_{\text {bond }}$ is bond strength (MPa), $F_{\text {ultimate }}$ is ultimate load (N), $A_{\text {bond }}$ is bonding area $\left(\mathrm{m}^{2}\right)$.

\section{Results and discussion}

\subsection{Microstructure}

Fig. 3 shows the SEM micrographs of the joint interfaces, which were bonded at different conditions. The left side for each micrograph indicates the LCS layer, and the right side does the HCCI layer. First, the difference in microstructure clearly reveals the bond line with wavy shape. When bonding temperature is at and below $1100{ }^{\circ} \mathrm{C}$ with a bonding strain rate of $0.001 \mathrm{~s}^{-1}$, as shown in Fig. 3(a)-(d), the LCS layer is characterised by allotriomorphic ferrite and pearlitic colony, while the HCCI layer consists of Cr-carbide blocks and secondary carbide particles embedded in the ferrous matrix. By raising the bonding temperature to $1150{ }^{\circ} \mathrm{C}$, the acicular ferrite mixed with pearlitic lamella occupies the left side regardless of bonding strain rate as shown in Fig. 3(e)-(h). Besides which, it can be seen that from Fig. 3(a)-(e), the volume fraction of pearlitic structure in the LCS layer increases with an increase of bonding temperature. According to the Kirkendall effect [18], atom moves from a region of high concentration to a region of low concentration during the diffusion process, especially at high temperatures. The Fick's laws of diffusion [18] indicate that the higher temperature is applied, the faster movement can be obtained due to the higher diffusion coefficient. For the current study, diffusion of C and Cr occurred apparently towards the LCS side because of their higher content in the HCCI layer (see Table 1). The solid segregation of $C$ near the interface on the left side is in favour of the transition of austenite to pearlite during air-cooling. The higher the austenitising temperature is, the higher the volume fraction of pearlite can be obtained. When diffusion was taking place together with plastic deformation, the movement of atoms was accelerated [19]. Fig. 4 shows the influence of bonding temperature and bonding strain rate on the diffusion of $\mathrm{Cr}$ across the interface by means of EDS analysis. As expected, Cr diffused from the HCCI to the LCS, which to a more extent with increasing bonding temperature. In Fig. 4(b), the diffusion is more active at the strain rate of $0.001 \mathrm{~s}^{-1}$ than the other three cases. This is attributed to the longer bonding time. 
In terms of the interface, the evolution is noticeable. As shown in Fig. 3, some voids and discontinuity on the bond line are found only for $950{ }^{\circ} \mathrm{C}$, whereas the bonded interface is in good condition by raising bonding temperature. When bonding temperature increases to $1100{ }^{\circ} \mathrm{C}$ with a bonding strain rate of $0.001 \mathrm{~s}^{-1}$, the phenomenon of intergrowth between the HCCI and the LCS is observed in Fig. 3(d). The intergrowth occurred in solid-state, which should be ascribed to the increase of element diffusion with bonding temperature. Thus, the same phenomenon can also be found at $1150{ }^{\circ} \mathrm{C} / 0.001 \mathrm{~s}$ ${ }^{1}$, as shown in Fig. 3(e). This joint mechanism is beneficial to the enhancement of bonding strength. However, as shown in Fig. 3(f)-(h), although the bonding temperature is as high as $1150{ }^{\circ} \mathrm{C}$, the intergrowth fades away with an increase of bonding strain rate due to insufficient diffusion time. In Fig. 3(e)-(h), a carbide-free zone is detected near the interface on the HCCI side at the bonding temperature of $1150{ }^{\circ} \mathrm{C}$, and the thickness of the zone decreases with an increase of bonding strain rate. EDS results as shown in Fig. 4(b) reveal that the depletion of Cr near the interface on the HCCI layer resulted in the formation of the carbide-free zone, and the decreasing bonding time at a higher bonding strain rate narrows the thickness of the depleted region. This transition zone is expected to improve the fracture toughness and bonding property of the bimetal. Oh et al. [6] and Kim et al. [7] also reported the similar carbide-free zone in the doucast materials.

Fig. 5 shows the OM micrographs of the HCCI layer with and without bonding treatments. It should be noted that the observations were conducted on the Y-Z plane (see Fig. 1(b)), which is parallel to the bonding interface. In as-cast state, as shown in Fig. 5(a), the fine rods of eutectic carbides grew radially from the periphery of the hexagonal carbide rods, and the long axes of the rods are perpendicular to the interface. By using image analysis technology, the volume fraction of Cr-carbide was calculated as 36.2\%, which is shown in Fig. 6(a). However, significant changes took place in the bimetal specimens. It can be seen that from Fig. 5(b)-(i), the carbide orientation, including fine and hexagonal carbide rods, rotates about $90^{\circ}$ regardless of bonding temperature (see Fig. 5(b)-(f)) and bonding strain rate (see Fig. 5(f)-(i)). In these cases, the long axes of the carbide rods are parallel to the interface. Moreover, the volume fraction of Cr-carbide increases with an increase of bonding temperature at a constant bonding strain rate as shown in Fig. 6(a), and Fig. 6(b) shows that the increasing bonding strain rate slightly lowers the volume fraction of Cr-carbide at a certain bonding temperature. Such a rapid increase 
resulted from the refinement of microstructure due to hot compression during the bonding process. Filipovic et al. [20] and Tang et al. [21] have demonstrated that increasing the volume fraction of Crcarbide is in favour of improving wear resistance by protecting ferrous matrix better from direct attack by abrasive particles.

In Fig. 5(b)-(h), the HCCI layer in the bimetal specimens was hot deformed successfully with crackfree, even though this alloy is prone to crack during plastic deformation. According to the research of Xie et al. [15, 16] and Masahashi et al. [22, 23], simultaneous deformation together with soft material is a beneficial method to deform the hard material by stress relief. Therefore, the "lubricating effect" of the LCS claddings contributed to stress relief for the HCCI layer during hot compression. However, some micro cracks are observed in Fig. 5(i), which presents the microstructure of the specimen boding at $1150{ }^{\circ} \mathrm{C} / 1 \mathrm{~s}^{-1}$. This is because the severe plastic deformation occurred at a high bonding strain rate cannot provide enough time to relieve soaring stress.

As previously mentioned, one distinguishing feature of the HCCI is that a high-volume fraction of Crcarbides in-situ embedded in a ferrous matrix. Thus, there are a large number of interfaces between carbide and matrix. When hot compression bonding was proceeded, local delamination probably occurred if the bonding conditions are improper. The delaminated interface may originate cracks as shown in Fig. 5(i), or the carbide may fall off easily due to out of constrains as indicated by the red circles in Fig. 5. These defects are likely to deteriorate the wear resistance of the HCCI by increasing wear rate. Fig. 7 shows the volume fraction of carbide pits of the HCCI layer with and without bonding treatments after polishing to $1 \mu \mathrm{m}$ diamond finish. The results were obtained by averaging 10 measurements using image analysis on micrographs at low magnifications. It can be found that from Fig. 7(a), the higher bonding temperature was applied, the lower volume fraction of carbide fell off from the specimens. When bonding temperature increases to $1150{ }^{\circ} \mathrm{C}$ with a bonding strain rate of $0.001 \mathrm{~s}^{-1}$, the lowest value was obtained. However, as shown in Fig. 7(b), although the bonding temperature was kept at $1150{ }^{\circ} \mathrm{C}$, the volume fraction of carbide pits increases significantly by raising the bonding strain rate.

Fig. 8 shows the influence of bonding temperature on the microstructure of the HCCI. As can be seen, 
the main phase of the as-cast HCCI is composed of $\mathrm{M}_{7} \mathrm{C}_{3}$ type carbide (where $\mathrm{M}$ includes $\mathrm{Cr}$, Fe and other strong carbide formers), martensite and retained austenite. When bonding temperature is at and below $1050{ }^{\circ} \mathrm{C}$, the phase components are similar to that of the as-cast one, except that the XRD patterns show an increase in the intensity of $\mathrm{M}_{23} \mathrm{C}_{6}$ type secondary carbide peaks. While at $1100{ }^{\circ} \mathrm{C}$, the intensity of the austenite peaks begins to increase, and a further increase is found at $1150{ }^{\circ} \mathrm{C}$. Thus, the retained austenite content in the HCCI layer increases with an increase of bonding temperature. Tabrett et al. [3] suggested that the $\mathrm{C}$ solubility in austenite can be increased by raising destabilisation temperature, which may reduce the driving force for carbide precipitation and decrease the transition temperature of austenite to martensite. This results in an increase of retained austenite content. In addition, it is interesting to note that the diffraction intensities of the XRD patterns reduce gradually with increasing bonding temperature, which indicates the textures may have been changed. It is in agreement with the changes of carbide orientation as shown in Fig. 5.

\subsection{Mechanical properties}

The microhardness profiles taken across the interface for the bimetal specimens are shown in Fig. 9(a) and (b) as a function of bonding temperature and bonding strain rate, respectively. It should be noted that the Vickers indentations on the HCCI layer were conducted on the ferrous matrix without massive carbides. In general, the hardness values decrease towards the LCS side in all the bonding conditions. This can be related to the lower C and alloy contents on the bond line and the LCS side [14] as demonstrated in Fig. 4. For the HCCI layer, the hardness decreases as the bonding temperature and bonding strain rate increased. The former is attributed to the increase of retained austenite content, which has been discussed in Fig. 8. While the latter contradicts with the conventional view of work hardening increasing with an increase of strain rate. In order to reveal the mechanism, the HCCI treated at different strain rates was analysed by SEM in a high magnification. Fig. 10(a) and (b) shows the SEM micrographs of the HCCI layer in the bimetal specimens bonding at $1150{ }^{\circ} \mathrm{C} / 0.001 \mathrm{~s}^{-1}$ and 1150 ${ }^{\circ} \mathrm{C} / 0.1 \mathrm{~s}^{-1}$, respectively. Plenty of fine secondary carbides disperse in the ferrous matrix is observed in Fig. 10(a), which is responsible for the increase of hardness at a lower bonding strain rate. For the LCS layer, a higher hardness was obtained at a higher bonding temperature because of the increasing volume fraction of pearlitic structure as shown in Fig. 3. 
Fig. 11(a) and (b) shows the bond shear strength as a function of bonding temperature and bonding strain rate, respectively. In Fig. 11(a), the profile can be separated into three parts: (i) bonding temperature $<1000{ }^{\circ} \mathrm{C}$, (ii) $1000{ }^{\circ} \mathrm{C} \leq$ bonding temperature $<1100{ }^{\circ} \mathrm{C}$ and (iii) bonding temperature $\geq$ $1100{ }^{\circ} \mathrm{C}$. In part (i), the lowest shear strength was obtained due to lack of bonding as shown in Fig. 3(a). By ascending the temperature to part (ii), the strength value was increased by approximately 21.3\%. Fig. 12(a) shows the fracture surface of the bimetal specimen bonding at $1000{ }^{\circ} \mathrm{C} / 0.001 \mathrm{~s}^{-1}$, which is characterised by shear band and cleavage fracture. When bonding temperature is at and above $1100{ }^{\circ} \mathrm{C}$, a further improvement of the shear strength was achieved by the enhancement of element diffusion. The fracture surface of the bimetal specimen bonding at $1150{ }^{\circ} \mathrm{C} / 0.001 \mathrm{~s}^{-1}$ is presented in Fig. 12(b), which reveals the shear band combined with dimple fracture dominates the shear process. However, since the diffusion time decreases as the bonding strain rate increased, the shear strength of the bimetal specimens was reduced linearly as shown in Fig. 11(b), even though the bonding temperature is as high as $1150{ }^{\circ} \mathrm{C}$. Fig. 12 (c) indicates that extensive cleavage fracture dominates the shear process of the bimetal specimen bonding at $1150{ }^{\circ} \mathrm{C} / 0.01 \mathrm{~s}^{-1}$. Eroglu and Kurt [14] also reported that the bond strength increased as the bonding temperature and holding time increased in the diffusion bonding process.

\section{Conclusions}

The sandwich structural bimetal consisting of HCCI as the core and LCS as the claddings was prepared by a hot diffusion-compression bonding process in a wide range of temperatures and strain rates with a constant engineering strain of 0.7 . The effects of bonding temperature and bonding strain rate on microstructure, hardness and bond strength of the bimetal were investigated. The following conclusions are drawn from this work.

(1) Micro voids and discontinuity on the bond line are detected only for $950{ }^{\circ} \mathrm{C}$, while the interface is in good condition for the other cases. Therefore, to achieve sound metallurgical bond, the bonding temperature should be higher than $950{ }^{\circ} \mathrm{C}$.

(2) When bonding temperature is at and above $1100{ }^{\circ} \mathrm{C}$, the phenomenon of intergrowth between the 
HCCI and the LCS was observed. When bonding temperature increases to $1150{ }^{\circ} \mathrm{C}$, a carbide-free zone near the interface on the HCCI layer was found regardless of bonding strain rate.

(3) The volume fraction of Cr-carbide on the HCCI layer was significantly increased by the bonding treatments, which to a more extent at a higher bonding temperature and a lower bonding strain rate. Moreover, the carbide orientation was rotated about $90^{\circ}$ by the hot compression process.

(4) The volume fraction of carbide pits decreases significantly with an increase of bonding temperature and a decrease of bonding strain rate. To obtain sound HCCI after severe plastic deformation, a high temperature with a low strain rate must be used in the bonding process.

(5) The hardness of the HCCI layer decreases as bonding temperature and bonding strain rate increased. The former is due to the increase of retained austenite content, while the latter is attributed to the decrease of precipitation of secondary carbides at a higher strain rate.

(6) Both rising bonding temperature and reducing bonding strain rate are in favour of the improvement of bond strength. The highest interface shear strength was obtained for the bimetal specimen bonding at $1150{ }^{\circ} \mathrm{C} / 0.001 \mathrm{~s}^{-1}$.

\section{Acknowledgements}

The first author would like to acknowledge the China Scholarship Council (CSC) and UOW IPTA for supporting the current research work. The authors are grateful to Mr Bob de Jong and Dr Liang Chen for the help of hot diffusion-compression bonding tests.

\section{References}

[1] Dogan ON, Hawk JA, Laird II G. Solidification structure and abrasion resistance of high chromium white irons. Metall Mater Trans A 1997; 28: 1315-28.

[2] Carpenter SD, Carpenter D, Pearce JTH. XRD and electron microscope study of an as-cast 26.6\% chromium white iron microstructure. Mater Chem Phys 2004; 85: 32-40.

[3] Tabrett CP, Sare IR, Ghomashchi MR. Microstructure-property relationships in high chromium white iron alloys. Int Mater Rev 1996; 41: 59-82.

[4] Gahr KHZ, Doane DV. Optimizing fracture toughness and abrasion resistance in white cast irons. 
Metall Trans A 1980; 11: 613-20.

[5] Sare IR. Abrasion resistance and fracture toughness of white cast irons. Mater Sci Tech-Lond 1979; 6: 412-9.

[6] Oh H, Lee S, Jung JY, Ahn S. Correlation of microstructure with the wear resistance and fracture toughness of duocast materials composed of high-chromium white cast iron and low-chromium steel. Metall Mater Trans A 2001; 32: 515-24.

[7] Kim CK, Lee S, Jung JY. Effects of heat treatment on wear resistance and fracture toughness of duo-cast materials composed of high-chromium white cast iron and low-chromium steel. Metall Mater Trans A 2006; 37: 633-43.

[8] Sallam HEM, Abd El-Aziz Kh, Abd El-Raouf H, Elbanna EM. Failure analysis and flexural behavior of high chromium white cast iron and AISI4140 steel bimetal beams. Mater Des 2013; 52: 974-80.

[9] Cholewa M, Wróbel T, Tenerowicz S, Szuter T. Diffusion phenomena between alloy steel and gray cast iron in layered bimetallic casting. Arch Metall Mater 2010; 55: 771-7.

[10] Xiong B, Cai C, Lu B. Effect of volume ratio of liquid to solid on the interfacial microstructure and mechanical properties of high chromium cast iron and medium carbon steel bimetal. J Alloys Compd 2011; 509: 6700-4.

[11] Xiong B, Cai C, Wan H, Lu B. Fabrication of high chromium cast iron and medium carbon steel bimetal by liquid-solid casting in electromagnetic induction field. Mater Des 2011; 32: 2978-82.

[12] Xiao XF, Ye SP, Yin WX, Xue Q. HWCI/carbon steel bimetal liner by liquid-liquid compound lost foam casting. J Iron Steel Res Int 2012; 19(10): 13-9.

[13] Sakurai I, Maedono H, Matsuo K, Momono T, Katayama HG. Diffusion bonding of high chromium cast iron to cast steel in air. Imono 1996; 68: $43-8$ (in Japanese).

[14] Eroglu M, Kurt B. Diffusion bonding between high chromium white iron and low carbon steel. Mater Sci Tech-Lond 2007; 23: 171-6.

[15] Xie G, Sheng H, Han J, Liu J. Fabrication of high chromium cast iron/low carbon steel composite material by cast and hot rolling process. Mater Des 2010; 31: 3062-6.

[16] Xie G, Han J, Liu J, Jiang Z. Texture, microstructure and microhardness evolution of a hot-rolled high chromium cast iron. Mater Sci Eng A 2010; 527: 6251-4.

[17] Defining a New Era in Physical Simulation and Thermal-Mechanical Testing. http://gleeble.com; 
2014.

[18] Cui ZQ. Metallurgy and heat treatment. 2nd ed. Bejing: China Machine Press; 2007 (in Chinese).

[19] Duan H, Kocak M, Bohm KH, Ventzke V. Transient liquid phase (TLP) bonding of TiAl/Ti6242 with Ti-Cu foil. Sci Technol Weld Joining 2004; 9: 525-31.

[20] Filipovic M, Kamberovic Z, Korac M, Gavrilovski M. Correlation of microstructure with the wear resistance and fracture toughness of white cast iron alloys. Met Mater Int 2013; 19: 473-81.

[21] Tang XH, Chung R, Li DY, Hinckley B, Dolman K. Variations in microstructure of high chromium cast irons and resultant changes in resistance to wear, corrosion and corrosive wear. Wear 2009; 267: 116-21.

[22] Masahashi N, Watanabe S, Hanada S, Komatsu K, Kimura G. Fabrication of iron aluminum alloy/steel laminate by clad rolling. Metall Mater Trans A 2006; 37: 1665-73.

[23] Masahashi N, Komatsu K, Watanabe S, Hanada S. Microstructure and properties of iron aluminum alloy/CrMo steel composite prepared by clad rolling. J Alloy Compd 2004; 379: 272-9.

\section{Figure captions}

Fig. 1. History of hot diffusion-compression bonding process (a) and schematic diagram of sandwich structural assembly (b).

Fig. 2. Schematic diagram of shear strength test apparatus.

Fig. 3. SEM micrographs of the bonding interface of bimetal: (a) $950{ }^{\circ} \mathrm{C} / 0.001 \mathrm{~s}^{-1}$, (b) $1000{ }^{\circ} \mathrm{C} / 0.001 \mathrm{~s}^{-}$ ${ }^{1}$, (c) $1050{ }^{\circ} \mathrm{C} / 0.001 \mathrm{~s}^{-1}$, (d) $1100{ }^{\circ} \mathrm{C} / 0.001 \mathrm{~s}^{-1}$, (e) $1150{ }^{\circ} \mathrm{C} / 0.001 \mathrm{~s}^{-1}$, (f) $1150{ }^{\circ} \mathrm{C} / 0.01 \mathrm{~s}^{-1}$, (g) 1150 ${ }^{\circ} \mathrm{C} / 0.1 \mathrm{~s}^{-1}$, (h) $1150{ }^{\circ} \mathrm{C} / 1 \mathrm{~s}^{-1}$. The left side is LCS, and the right side is HCCI.

Fig. 4. Variation of Cr content as a function of distance from interface at different bonding conditions: (a) $0.001 \mathrm{~s}^{-1}$, (b) $1150{ }^{\circ} \mathrm{C}$. Distance $>0$ is HCCI, and distance $<0$ is LCS.

Fig. 5. OM micrographs showing microstructure of the HCCI layer in Y-Z plane: (a) as-cast, (b) 950 ${ }^{\circ} \mathrm{C} / 0.001 \mathrm{~s}^{-1}$, (c) $1000{ }^{\circ} \mathrm{C} / 0.001 \mathrm{~s}^{-1}$, (d) $1050{ }^{\circ} \mathrm{C} / 0.001 \mathrm{~s}^{-1}$, (e) $1100{ }^{\circ} \mathrm{C} / 0.001 \mathrm{~s}^{-1}$, (f) $1150{ }^{\circ} \mathrm{C} / 0.001 \mathrm{~s}^{-1}$, (g) $1150{ }^{\circ} \mathrm{C} / 0.01 \mathrm{~s}^{-1}$, (h) $1150{ }^{\circ} \mathrm{C} / 0.1 \mathrm{~s}^{-1}$, (i) $1150{ }^{\circ} \mathrm{C} / 1 \mathrm{~s}^{-1}$.

Fig. 6. Volume fraction of Cr-carbide of the HCCI layer as a function of (a) bonding temperature when strain rate is $0.001 \mathrm{~s}^{-1}$ and (b) bonding strain rate when temperature is $1150{ }^{\circ} \mathrm{C}$.

Fig. 7. Volume fraction of carbide pits of the HCCI layer as a function of (a) bonding temperature when 
strain rate is $0.001 \mathrm{~s}^{-1}$ and (b) bonding strain rate when temperature is $1150{ }^{\circ} \mathrm{C}$.

Fig. 8. XRD patterns of the as-cast HCCI and the HCCI layer in the bimetal specimens bonding at different temperatures.

Fig. 9. Variation of microhardness as a function of distance from interface at different bonding conditions: (a) $0.001 \mathrm{~s}^{-1}$, (b) $1150{ }^{\circ} \mathrm{C}$. Distance $>0$ is HCCI, and distance $<0$ is LCS.

Fig. 10. SEM micrographs of the HCCI layer in the bimetal specimens bonding at (a) $1150{ }^{\circ} \mathrm{C} / 0.001 \mathrm{~s}^{-}$ , (b) $1150{ }^{\circ} \mathrm{C} / 0.1 \mathrm{~s}^{-1}$.

Fig. 11. Interface shear strength as a function of (a) bonding temperature when strain rate is $0.001 \mathrm{~s}^{-1}$ and (b) bonding strain rate when temperature is $1150{ }^{\circ} \mathrm{C}$.

Fig. 12. SEM micrographs showing the typical fracture surfaces of the bimetal specimens bonding at (a) $1000{ }^{\circ} \mathrm{C} / 0.001 \mathrm{~s}^{-1}$, (b) $1150{ }^{\circ} \mathrm{C} / 0.001 \mathrm{~s}^{-1}$, (c) $1150{ }^{\circ} \mathrm{C} / 0.01 \mathrm{~s}^{-1}$. 
Table 1 Chemical compositions of the HCCI and the LCS (wt \%).

\begin{tabular}{cccccccccc}
\hline Material & $\mathrm{C}$ & $\mathrm{Si}$ & $\mathrm{Mn}$ & $\mathrm{P}$ & $\mathrm{S}$ & $\mathrm{Cr}$ & $\mathrm{Ni}$ & $\mathrm{Mo}$ & $\mathrm{Cu}$ \\
\hline HCCI & 2.4 & 1.2 & 0.9 & 0.02 & 0.03 & 23 & 0.3 & 0.5 & 0.1 \\
LCS & 0.1 & 0.15 & 1.61 & 0.014 & 0.002 & 0.21 & $/$ & $/$ & $/$ \\
\hline
\end{tabular}


Fig. 1.

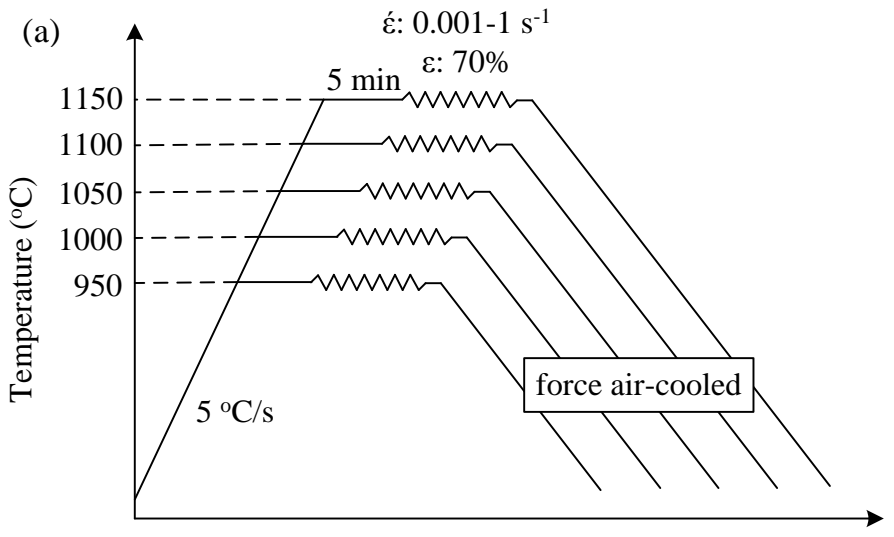

(b)

Time (min)

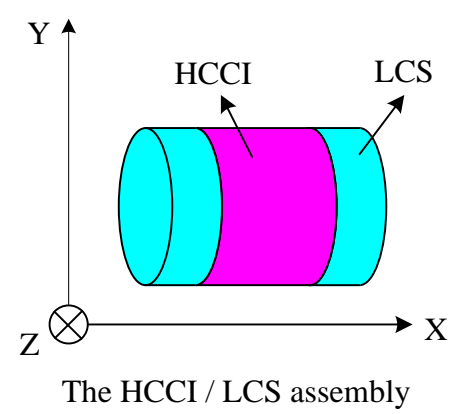


Fig. 2.

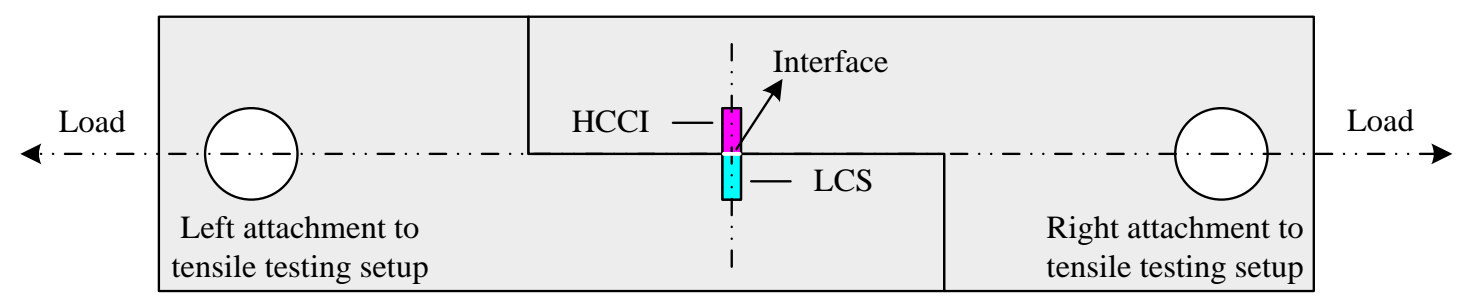


Fig. 3.
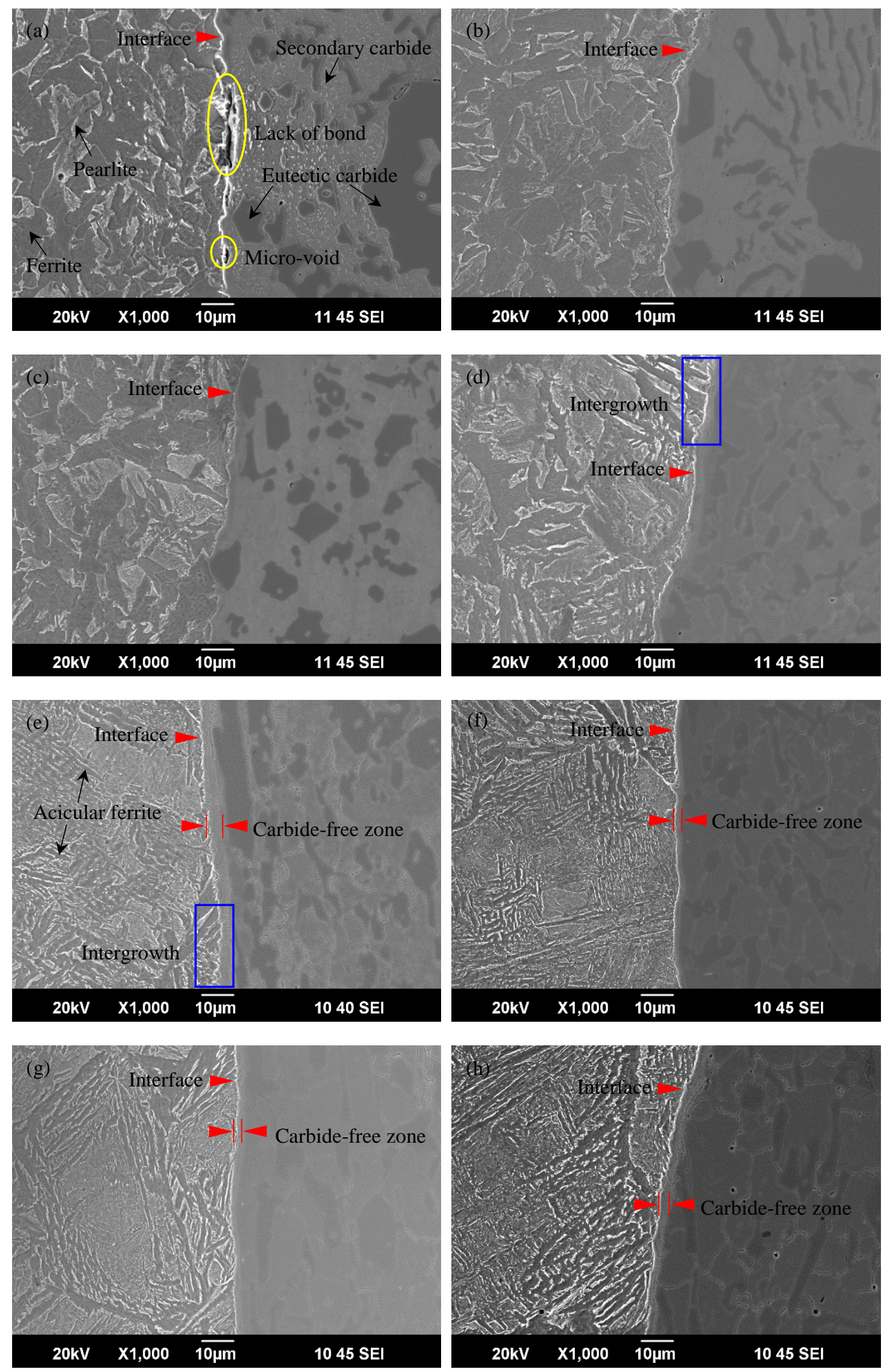
Fig. 4.
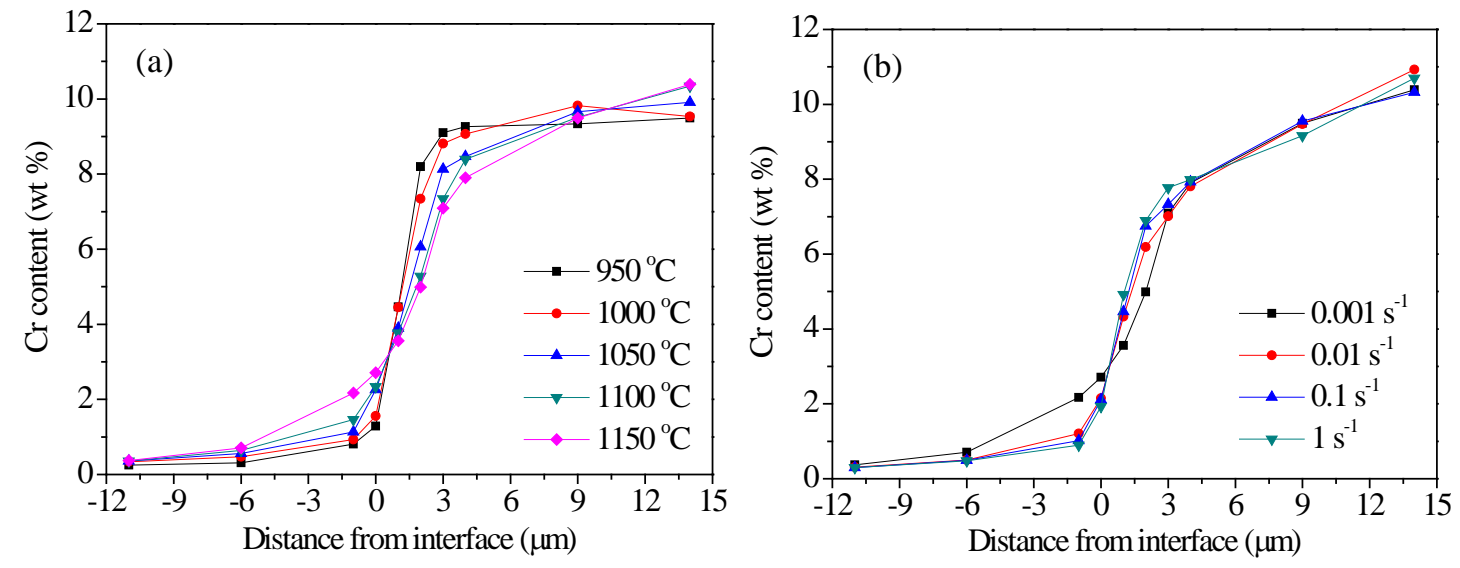
Fig. 5.
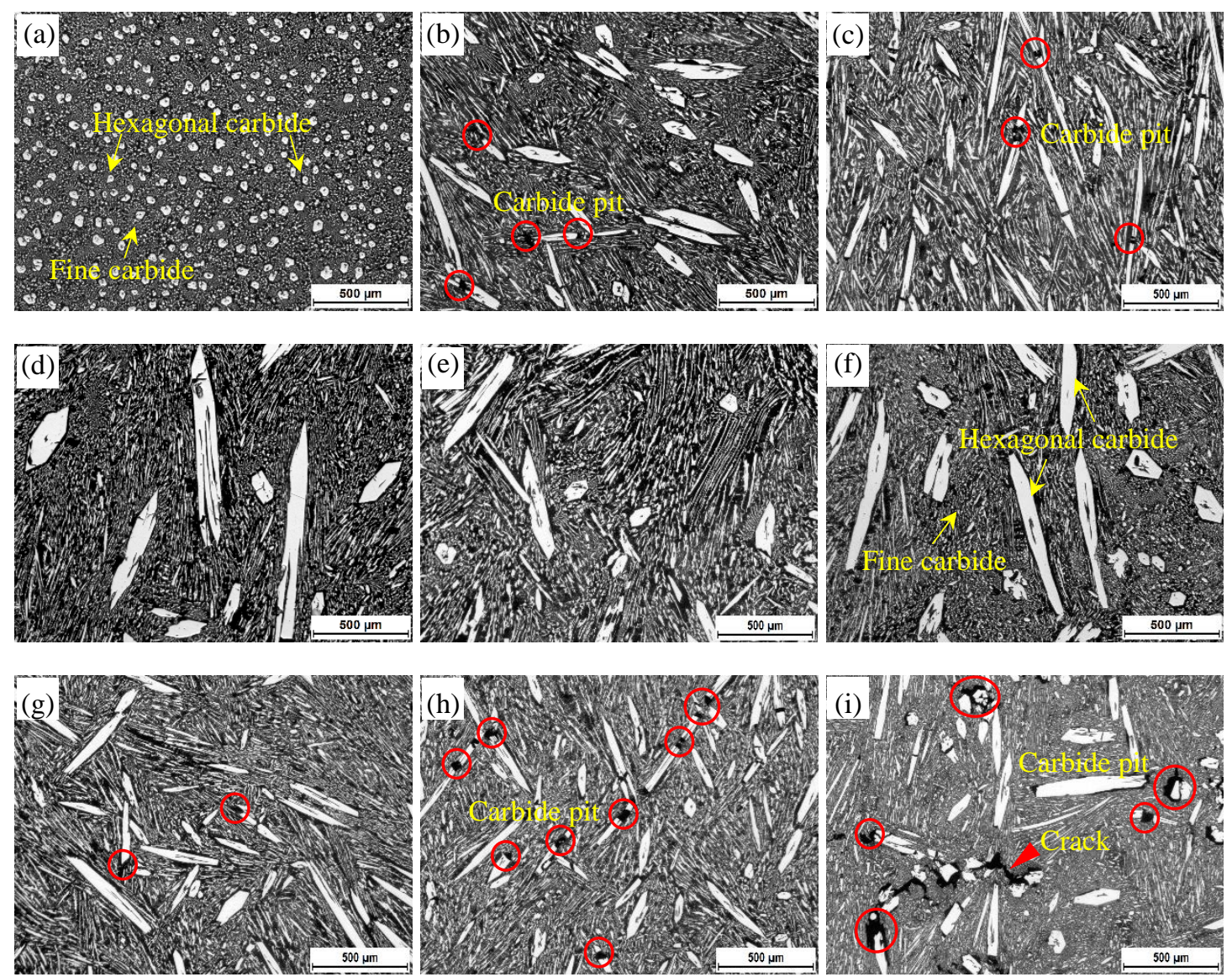
Fig. 6.
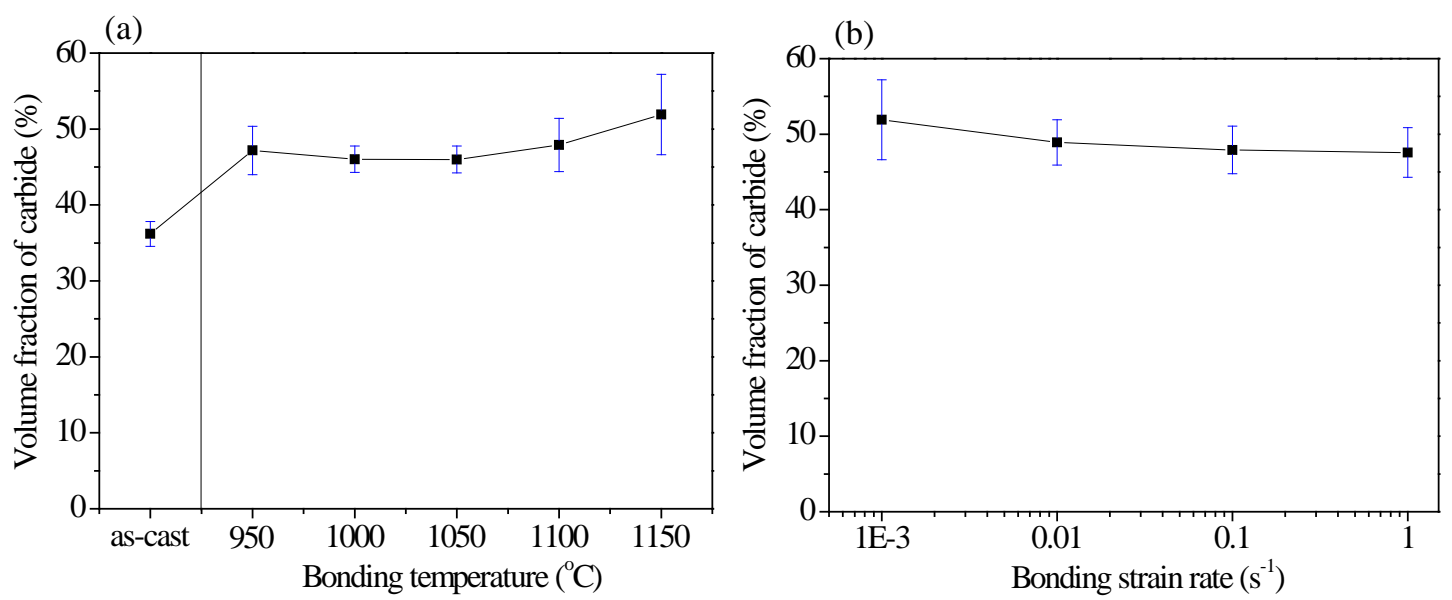

20 
Fig. 7.
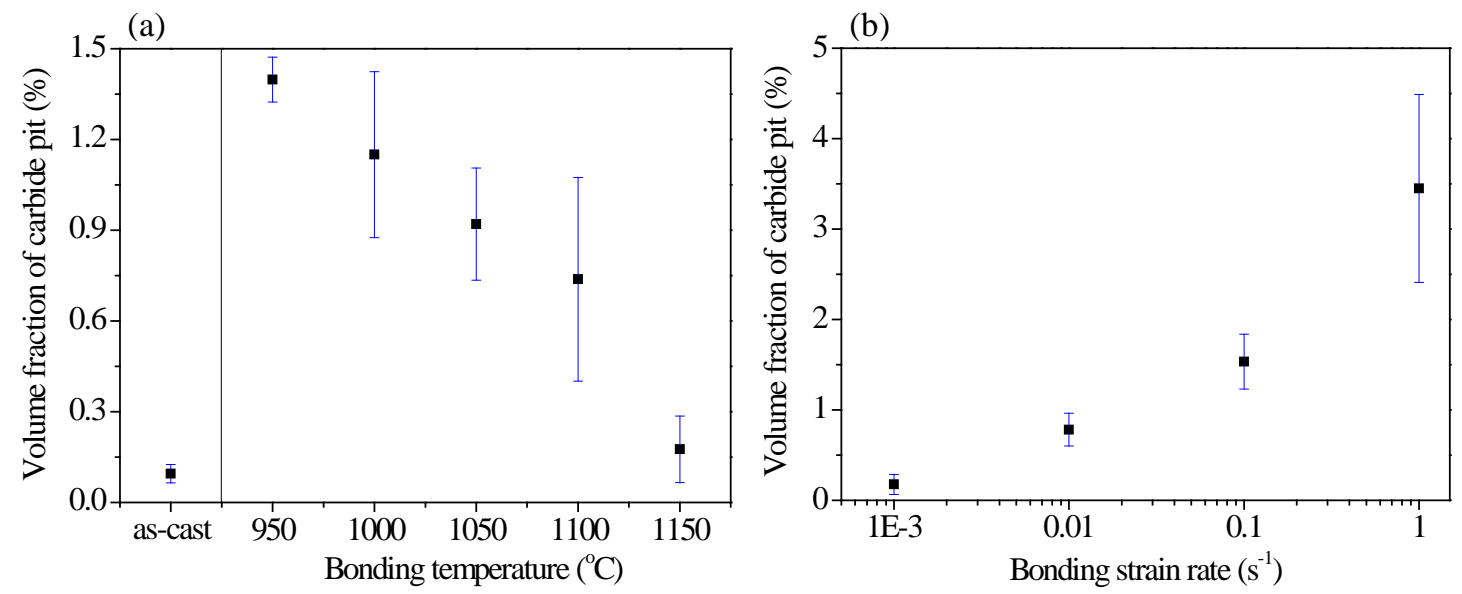
Fig. 8.

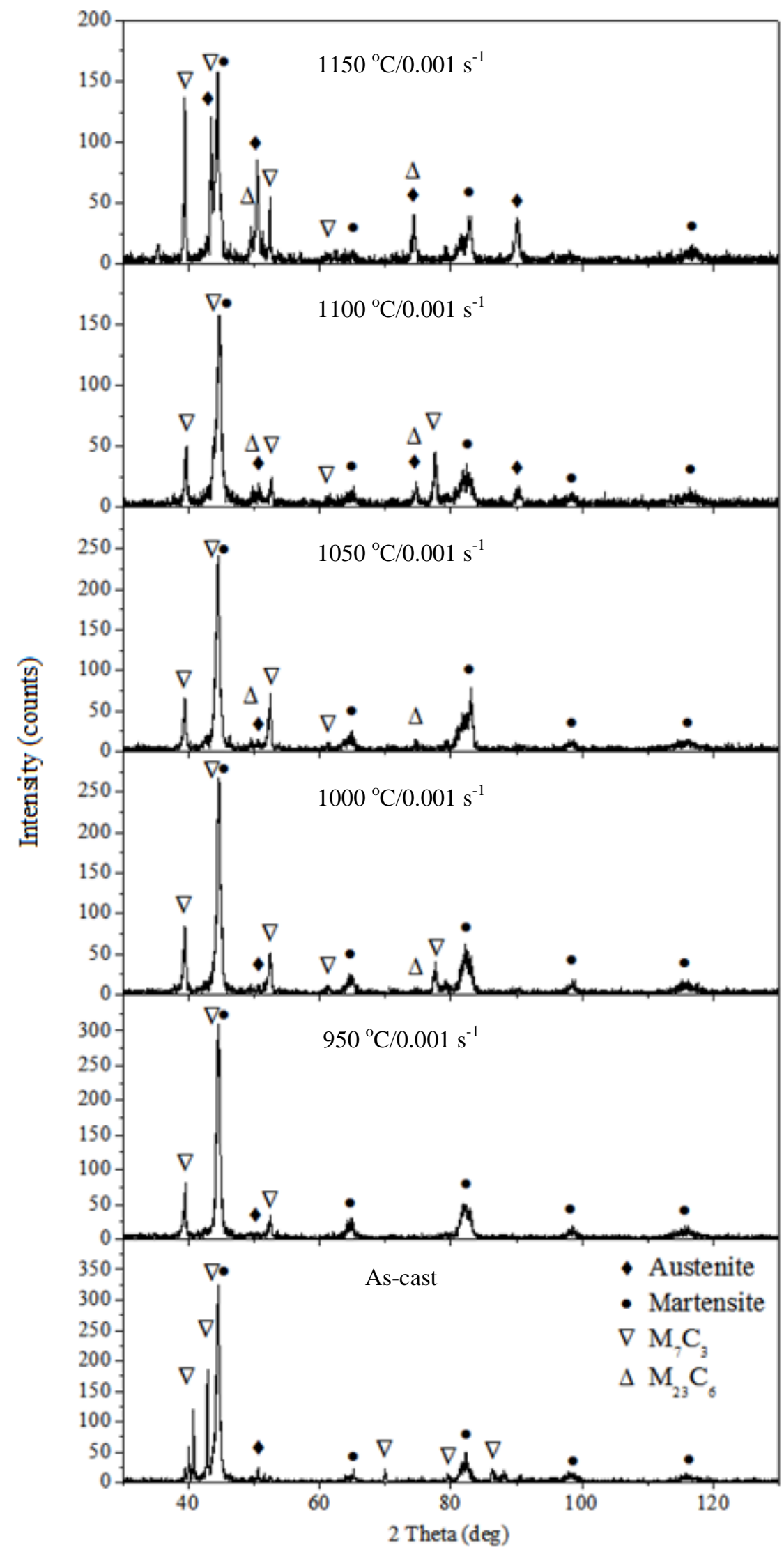


Fig. 9.
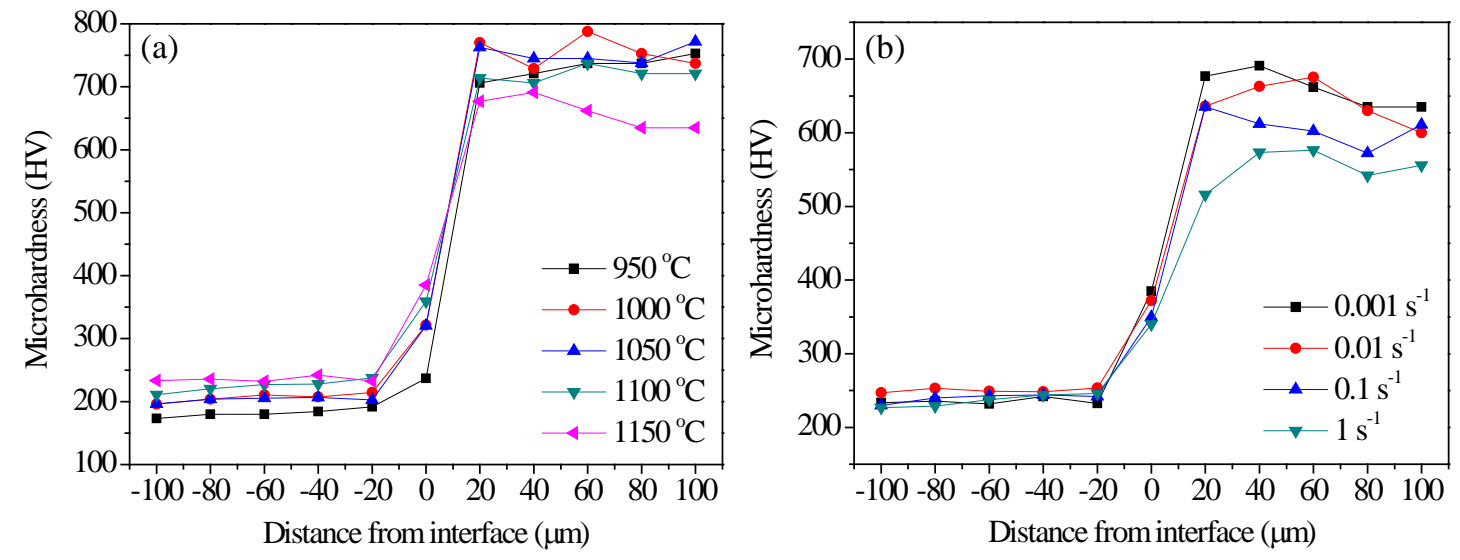
Fig. 10.
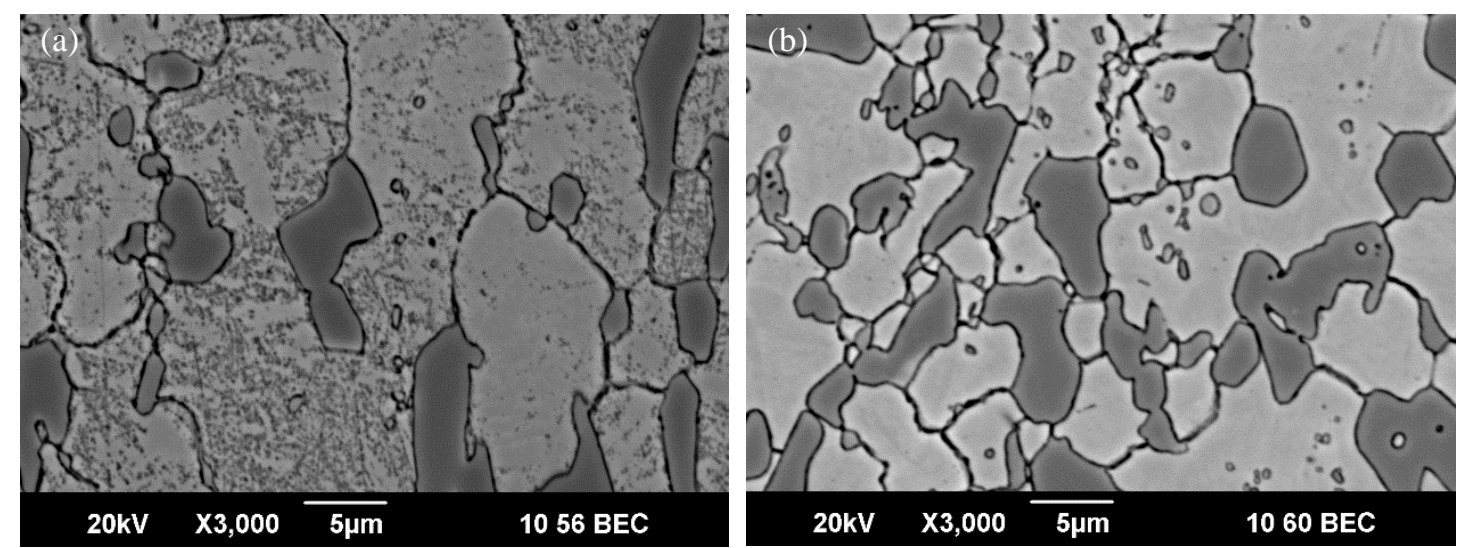
Fig. 11.
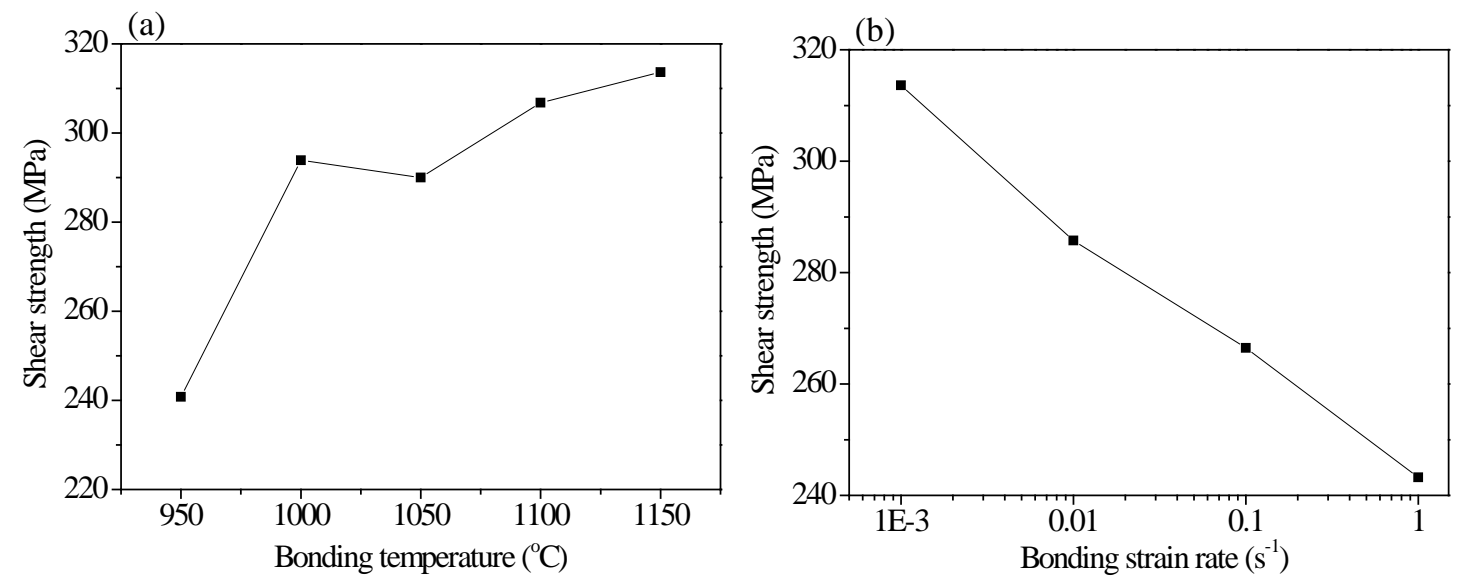
Fig. 12.
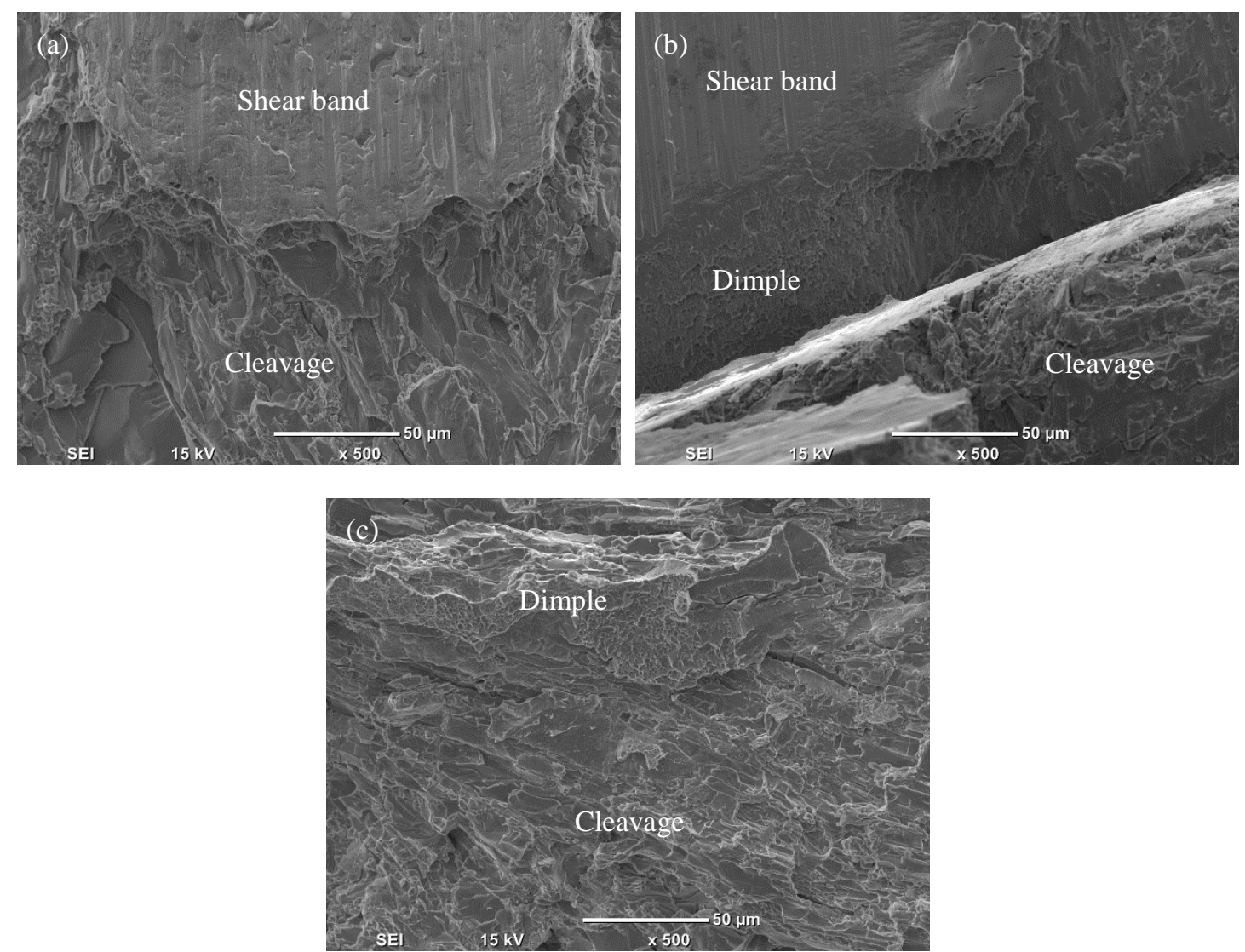